\title{
Transcatheter pulmonary valve in failed bioprosthesis
}

\author{
Dhaval R. Parekh ${ }^{1,2,3}$, Athar M. Qureshi ${ }^{1,2}$ \\ ${ }^{1}$ Department of Pediatrics, Baylor College of Medicine, Houston, TX, USA; ${ }^{2}$ The Lillie Frank Abercrombie Section of Cardiology, Texas Children's \\ Hospital, Houston, TX, USA; ${ }^{3}$ Texas Heart Institute, Houston, TX, USA \\ Correspondence to: Dhaval R. Parekh, MD. Texas Children's Hospital, Legacy Tower 20th FL, 6651 Main St., Houston, TX 77030, USA. \\ Email: dparekh@bcm.edu.
}

Submitted Aug 17, 2021. Accepted for publication Sep 02, 2021.

doi: 10.21037/acs-2021-tviv-29

View this article at: https://dx.doi.org/10.21037/acs-2021-tviv-29

\section{Clinical vignette}

Case one is a 38-year-old male born with pulmonary atresia, ventricular septal defect (VSD) and major aorto-pulmonary collaterals. He underwent serial repairs with VSD closure and staged unifocalizations and right pulmonary artery stenting. His latest operation was placement of a $25-\mathrm{mm}$ Hancock porcine valved conduit. He now presents with associated stenosis and regurgitation following fifteen years of progressive mixed conduit dysfunction.

Case two is a 24-year-old male born with tetralogy of Fallot. He underwent prior right modified Blalock-TaussigThomas shunt placement, subsequent shunt takedown and placement of a 14-mm homograft, later upsized to a $15-\mathrm{mm}$ homograft. His last operation was placement of a $20-\mathrm{mm}$ Contegra conduit (Medtronic, Minnesota, USA). He now presents with a dysfunctional fourteen-year-old, 20-mm Contegra conduit and symptoms of dyspnea associated with mixed conduit stenosis and regurgitation.

\section{Catheterization technique}

\section{Preparation of set up}

Under general endotracheal anesthesia, a standard patient preparation is undertaken with biplane if available.

\section{Standard approach}

Access with a 6-F common femoral venous sheath via ultrasound guidance using micropuncture technique is utilized. Next, a Perclose Proglide ${ }^{\mathrm{TM}}$ (Abbott, Plymouth, MN, USA) may be undertaken and then upsized to an 11-F short sheath. The right internal jugular vein may be accessed for known groin occlusions and allows for improved maneuvering through a large compliant right atrium compared to femoral approach. Arterial access is achieved with a $5-\mathrm{F}$ femoral, or radial sheath and a pigtail catheter is positioned in the ascending aorta for arteriogram visualizing the proximal coronaries and for root compression.

\section{Key technique}

A flow directed balloon tipped catheter is advanced to the distal branch of the pulmonary artery based on anatomy and exchanged for a stiff wire guide, typically a Lunderquist (Cook, Bloomington, IN, USA). The balloon end hole is replaced with either an 8-F Multi-Track ${ }^{\mathrm{TM}}$ catheter (B. Braun, Bethlehem, PA, USA) or a 7-F Judkins right or multipurpose guide catheter for pulmonary angiography.

Next, a rupture resistant long shaft balloon, typically a Vida or True balloon (Becton Dickinson Franklin Lakes, NJ, USA), is selected several mm smaller than the intended valve implant for predilation and assessment of potential coronary impingement.

Simultaneous predilation of the pulmonary bioprosthesis and careful coronary examination using multiple angulated views, we prefer lateral and steep LAO Caudal angulation, is undertaken with a power injection in the aortic root. The lack of cardiac output with the pulmonary bioprosthesis balloon occluded, allows for excellent imaging of the coronaries to evaluate for impingement. We prefer a root injection in addition to selective coronary angiography when needed, as occasionally compression of the aortic root and coronary ostia is detected which may go unnoticed with selective angiography. 
The largest implantable percutaneous valve is selected based on true internal diameter measurement nomograms of the failed bioprosthesis and axial computed tomography (CT) axial imaging. The Melody valve (Medtronic, Minneapolis, MN, USA) is tested to have optimal function at $22 \mathrm{~mm}$ in diameter but have been effectively dilated to $24 \mathrm{~mm}$ without residual dysfunction. All larger bioprosthesis require either a 26- or 29-mm Sapien valve (Edwards, Irvine, CA, USA) placement (1). The Melody valve is hand crimped with one or two Palmaz XL (Cordis, Santa Clara, CA, USA) 3110 stent(s) superimposed on the valve. The Palmaz stent acts as reinforcement and prevents recoil of the Melody valve which is comprised of a platinum iridium stent frame with limited radial strength and prone to fatigue and fracture $(2,3)$.

The Melody valve and Palmaz stent are secured via umbilical tape on the balloon-in-balloon (BiB) 22-F delivery Ensemble which acts as covered sheath traversing the right heart anatomy. Once positioned, the outer white sheath is retracted and the in inner balloon is inflated slowly, allowing for minor adjustments. Ultimately the outer balloon is inflated to fully deploy the valve. Pacing is not usually required but breath hold may be helpful.

The Sapien valve in contrast requires a crimper and when crimped a second time, allows for the smaller profile to be delivered through Gore Dryseal sheath (Gore, Flagstaff, AZ, USA) (4). The 22-F $65-\mathrm{cm}$ sheath can accommodate up to a $26-\mathrm{mm}$ Sapien and the $29-\mathrm{mm}$ valve requires a 24-F $65-\mathrm{cm}$ sheath. This allows for Sapien valve to be advanced through the tricuspid valve and chordal apparatus fully protected limiting injury. Once positioned the center marker on the Sapien should be slightly distal to center on the bioprosthesis as it tends to foreshorten more from the bottom. The increased radial strength of Sapien stent frame allows for sole deployment without the need for additional Palmaz stent reinforcement.

Given the severe right pulmonary artery stenosis in case two, predilation with a $10-\mathrm{mm}$ Mustang balloon (Boston Scientific, Marlborough, MA) was undertaken and due to recoil a short Max LD 26-mm stent (Medtronic, Minneapolis, MN, USA) was prepped and mounted on a 14-mm BiB catheter (B. Braun, Bethlehem, PA, USA) and deployed through a 14-F long sheath, being careful not to encroach on the main pulmonary artery.

\section{Completion of procedure and closure}

Post dilatation with a rupture resistant balloon of the same size as the deployed valve may be required. Some operators utilize transesophageal or intracardiac echocardiography guidance to assess valve position and function. Closure is completed with Proglide suture or a figure-of-eight suture placed for external compression of venotomy. For most valve in valves $(\mathrm{ViV})$, we have resorted to short-term anticoagulation with an oral anticoagulant or at minimum dual antiplatelet agents for three to six months as tolerated. Subsequently, a lifelong low-dose aspirin and spontaneous bacterial endocarditis prophylaxis is observed.

\section{Comments}

Advantages to our simplified, minimalist approach for pulmonary ViV implantation include a single-step predilation and coronary impingement testing, a single-step Palmaz stent and Melody valve deployment and utilization of a long shaft Gore Dryseal sheath, to deliver a crimped Edwards Sapien valve in a covered fashion to minimize tricuspid injury. However, caution must be taken when combining these steps across product lines (and in other transcatheter pulmonary valve cases) as many variations of these techniques are required based on each individual case.

\section{Acknowledgments}

Funding: None.

\section{Footnote}

Conflicts of Interest: Dr. AMQ has consulting relationships with Medtronic, Edwards Lifesciences, W.L. Gore \& Associates, and Abiomed Inc. Dr. DRP has no conflicts of interest to declare.

Open Access Statement: This is an Open Access article distributed in accordance with the Creative Commons Attribution-NonCommercial-NoDerivs 4.0 International License (CC BY-NC-ND 4.0), which permits the noncommercial replication and distribution of the article with the strict proviso that no changes or edits are made and the original work is properly cited (including links to both the formal publication through the relevant DOI and the license). See: https://creativecommons.org/licenses/by-nc-nd/4.0/.

\section{References}

1. Boone RH, Webb JG, Horlick E, et al. Transcatheter 
pulmonary valve implantation using the Edwards SAPIEN transcatheter heart valve. Catheter Cardiovasc Interv 2010;75:286-94.

2. Cabalka AK, Hellenbrand WE, Eicken A, et al. Relationships Among Conduit Type, Pre-Stenting, and Outcomes in Patients Undergoing Transcatheter Pulmonary Valve Replacement in the Prospective North American and European Melody Valve Trials. JACC Cardiovasc Interv 2017;10:1746-59.

Cite this article as: Parekh DR, Qureshi AM. Transcatheter pulmonary valve in failed bioprosthesis. Ann Cardiothorac Surg 2021;10(5):720-722. doi: 10.21037/acs-2021-tviv-29
3. Cabalka AK, Asnes JD, Balzer DT, et al. Transcatheter pulmonary valve replacement using the melody valve for treatment of dysfunctional surgical bioprostheses: A multicenter study. J Thorac Cardiovasc Surg 2018;155:1712-1724.e1.

4. Stapleton GE, Gowda ST, Bansal M, et al. SAPIEN S3 valve deployment in the pulmonary position using the gore DrySeal sheath to protect the tricuspid valve. Catheter Cardiovasc Interv 2020;96:1287-93. 